사상체질의학회지 2012;24(2):54-60

$\mathrm{J}$ of Sasang Constitutional Medicine

Vol. 24, No. 2, 2012:54-60

http://www.esasang.com

\title{
사상체질의학의 특허 동향 분석
}

\author{
진희정 · 김상혁 · 이시우
}

한구한의학연구원

\section{Abstract}

\section{Patent Analysis of Sasang Constitution Medicine \\ HœJeong Jin, Sang-Hyuk Kim, Si-Woo Le \\ Korea Institute of Oriental Medicine}

\section{Objectives}

The purpose of this study is to analyze for the patent application tendency in SCM (Sasang Constitutional M edicine). Recently, in SCM, many researches are made public through papers. However, in the patent area, the research results are less than the papers.

\section{Methods}

W e collected patents about SCM using wintelips program. W e analyzed patents according to the year, author, topic, and etc.

\section{Results}

W e collected 151 patents using search system with wintelips program. After detailed analysis on SCM patent, we got to know that SCM was a growing field. In the collected patents, the patents on diagnosis technology were the majority and system of providing information were the second largest.

\section{Conclusions}

W e think that the SCM field is growing at a fast pace with high activity, and this research should be updated annually.

Key Words: Sasang Constitutional M edicine, Sasang Diagnosis, Patent

• 접수일 2012년 05월 08일; 심사일 2012년 05월 22일;

승이일 2012년 06월 08일

- 표신저자 : OIN 우우

대전 $\wedge 1$ 유성구 전민동 461-24, 한국한의학연구원

체질의학임상연구센터

Tel : +82-42-868-9555 Fax : +82-42-868-9480

E-mail : bfree@kiom.re.kr
• 본 연구는 2012년도 정부(교육과학기술부)의 재원으로 한국연구 재단의 지원을 받아 수행되었습니다(No.20110027739).

- The Society of Sasang Constitutional Medicine. All rights reserved. This is an open acess article distributed under the terms of the Creative Commons attribution Non-commercial License(http:// creativecommons.org/licenses/by-nc/3.0/) 


\section{I. 緒 論}

30 억개의 인간의 염기서열이 밝혀지면서, 개인마 다 다른 염기 일부분의 차이(SNP, Single Nucleotide Polymorphism)를 바탕으로 한 개인맞춤의학의 시대가 도래 할 것이라 기대되었다. 하지만, 2000년 6월 인간 게놈 프로젝트(H uman Genome Project $)^{1}$ 의 결과가 나온 이후 십년의 세월이 흘렀지만, 개인맞춤의학의 연구 는 아직 초기 단계에 있으며, 대부분의 연구자들이 개인맞춤의학이 도래하기까지 아직 더 많은 연구가 진행되어야 함을 공감하고 있다.

사상체질의학은 사람의 체질에 따라 같은 병이라 하더라도 치료방법이 달라지며, 또한 질병의 치료뿐 만 아니라 건강한 삶을 위해 체질에 따라 사람의 몸과 마음의 균형을 잡을 수 있는 방법을 제시한다. 즉, 사 상체질의학은 개인맞춤의학이라 볼 수는 없지만, 전 체를 하나의 동일한 방법으로 치료하지 않고, 체질 집단에 따라 달리하기 때문에 집단맞춤의학이라 볼 수 있다.

최근 많은 사람들이 수명 연장뿐만 아니라 건강한 삶에 관심을 가지면서 전통적 맞춤의학이라 할 수 있 는 사상체질의학에 관한 연구들도 많이 진행되고 있 다. 2011년 한국한의학연구원에서 진행한 "국내외 체 질분야 연구 분석- $\mathrm{KCl}$ 및 $\mathrm{SCl}$ 데이터 분석을 중심으 로"자료를 살펴보면 2004년부터 2010년까지 총 9,731 편, 매년 평균 1,600 건이 넘는 논문이 발표되어 많은 연구들이 진행되고 있음을 알 수 있다. 하지만, 논문 발표 건수에 비해 연구결과를 특허 등록으로 진행하 는 경우는 많지 않다.

오늘날 지식재산의 중요성이 증가하면서, 많은 연 구자들이 자신의 연구 결과에 대한 특허권을 갖기 위 해 특허 출원 후 논문을 발표하는 형태를 취하고 있다. 이를 위해 각 연구들의 특허 출원 전 관련 특허 동향 분석이 활발히 이루어지고 있으며, 특히 최근 들어 특허정보는 특정 연구 분야의 기술예측에 사용되고 ${ }^{48}$, 이를 통하여 기업이나 연구부서에서의 정책수립에 중 요한 역할을 하고 있다. 덧붙여 OECD 국가에서는 특 허정보를 연구개발 혁신활동의 주요 성과로 평가하고 있는 추세이다.

본 연구에서는 체질연구를 주제로 한 국내 특허동
향을 분석함으로써, 최근 활발하게 연구되고 있는 체 질 연구 동향을 살펴보고 향후 진행될 체질연구의 방 향 수립에 도움이 되고자 한다.

\section{II. 分析 基準 咬 範圍}

본 연구에서는 특허분석을 위해 윈텔립스 특허분 석 프로그램(Patent Theme Search \& Smart Analysis Solution) ${ }^{10}$ 을 사용하여, 국내에서 등록된 모든 체질 관 련 특허를 조사하였다. 윈텔립스는 다양하고 편리한 검색기능과 통계분석 기능을 가진 특허 검색/분석 서 비스 툴로서, 윈텔립스에서 제공하는 한국 특허는 특 허/실용에 대해 매주 업데이트되어, 특허 검색에 유용 한 툴이라 볼 수 있다.

체질 관련 특허 검색하기 위해, 기술 범위는 특허 제목에 "사상체질" 또는 "체질"이라는 단어가 포함되 거나 특허 초록에 "사상체질"이라는 단어가 포함되어 있는 것으로 한정하였다. 특허식에 의하여 검색된 특 허 건수는 모두 961 건이었다. 이중 사상체질과 관련이 없는 특허들을 제거하는 전처리 과정을 거쳤다. 전처 리 과정에서는 “멜라민촉매를 사용하여 입방체질화 붕소를 제조하는 방법"와 같이 단순히 단어가 같을 뿐 의미가 다른 것과 “체질개선 수련시스템"과 같이 일반적으로 통용되는 허약체질과 같은 몸의 상태를 나타내는 용어로써 사용된 특허들을 제거하였다. 전 처리를 거친 특허는 모두 151 건이었다.

본 논문에서 사용한 기술 분석의 항목은 연도별 특허수와 추이, IPC 분류별 특허수와 연도별 IPC에 따른 특허수, 특허의 내용에 따른 분류, 출원인별 특허 수, 연도별 출원인에 따른 특허수이다.

\section{III. 分析 結果}

전처리 과정을 거친 특허는 모두 151개였다. Figure 1 은 연도별 특허수의 추이를 살펴본 것이다. 1992년에 처음 체질관련 특허가 등록된 이후 매년 꾸준하게 특 허가 등록되었으며, 특히 2000년 이후 특허수가 증가 되었음을 알 수 있다.(Figure. 1)

특허의 분류를 위해 국제특허분류(IPC) 클래스를 사용하여 분류별 체질특허수를 확인해보았다.(Table 1) 
Table 1. The Number of Each IPC Class

\begin{tabular}{|c|c|c|c|c|}
\hline & IPC & & \# & Description \\
\hline \multirow{7}{*}{$\begin{array}{l}\text { A } \\
(84)\end{array}$} & \multirow{7}{*}{$\begin{array}{l}\text { HUMAN } \\
\text { NECESSITIES }\end{array}$} & A01 & 1 & $\begin{array}{l}\text { AGRICULTURE | AGRICULTURE ; FORESTRY ; ANIMAL HUSBANDRY } \\
\text { HUNTING ; TRAPPING ; FISHING }\end{array}$ \\
\hline & & A23 & 19 & $\begin{array}{l}\text { FOODS OR FOODSTUFFS ; THEIR TREATMENT, NOT COVERED BY } \\
\text { OTHER CLASSES }\end{array}$ \\
\hline & & $\mathrm{A} 41$ & 7 & PERSONAL OR DOMESTIC ARTICLES | WEARING APPAREL \\
\hline & & A45 & 1 & HAND OR TRAVELLING ARTICLES \\
\hline & & A47 & 1 & FURNITUREarrangements of seats \\
\hline & & A61 & 54 & $\begin{array}{l}\text { HEALTH ; LIFE-SAVING ; AMUSEMENT | MEDICAL OR VETERINARY } \\
\text { SCIENCE ; HYGIENE }\end{array}$ \\
\hline & & A63 & 1 & SPORTS ; GAMES ; AMUSEMENTS \\
\hline \multirow{3}{*}{$\begin{array}{l}C \\
(7)\end{array}$} & \multirow{3}{*}{$\begin{array}{l}\text { CHEMISTRY; } \\
\text { METALLURGY }\end{array}$} & $\mathrm{CO2}$ & 1 & $\begin{array}{l}\text { TREATMENT OF WATER, WASTE WATER, SEWAGE, OR SLUDGEsettling } \\
\text { tanks, filtering, eg. sand filters or screening devices }\end{array}$ \\
\hline & & C11 & 1 & $\begin{array}{l}\text { ANIMAL OR VEGETABLE OILS, FATS, FATTY SUBSTANCES OR WAXES ; } \\
\text { FATTY ACIDS THEREFROM ; DETERGENTS; CANDLESedible oil or fat } \\
\text { compositions }\end{array}$ \\
\hline & & $\mathrm{C} 12$ & 5 & $\begin{array}{l}\text { BIOCHEMISTRY ; BEER ; SPIRITS ; WINE ; VINEGAR ; MICROBIOLOGY ; } \\
\text { ENZYMOLOGY ; MUTATION OR GENETIC ENGINEERING }\end{array}$ \\
\hline $\mathrm{E}(1)$ & $\begin{array}{l}\text { FIXED } \\
\text { CONSTRUCTIONS }\end{array}$ & E04 & 1 & $\begin{array}{l}\text { BUILDING | CONSTRUCTION OF ROADS, RAILWAYS, OR BRIDGESOf } \\
\text { tunnels }\end{array}$ \\
\hline $\mathrm{F}(1)$ & $\begin{array}{l}\text { MECHANICAL } \\
\text { ENGINEERING }\end{array}$ & F25 & 1 & $\begin{array}{l}\text { ENGINES OR PUMPS | MACHINES OR ENGINES IN GENERALcombustion } \\
\text { engines }\end{array}$ \\
\hline \multirow{4}{*}{$\begin{array}{l}G \\
(53)\end{array}$} & \multirow{4}{*}{ PHYSICS } & G01 & 2 & \begin{tabular}{l|l} 
INSTRUMENTS | MEASURING；TESTING \\
\end{tabular} \\
\hline & & G06 & 48 & $\begin{array}{l}\text { COMPUTING ; CALCULATING ; COUNTINGscore computers for games } \\
\text { A63B-071/06, A63D-015/20, A63F-001/18combinations of writing implements with } \\
\text { computing devices }\end{array}$ \\
\hline & & G07 & 2 & CHECKING-DEVICES \\
\hline & & G10 & 1 & MUSICAL INSTRUMENTS ; ACOUSTICS \\
\hline \multirow[t]{2}{*}{$\mathrm{H}(5)$} & ELECTRICITY & $\mathrm{H} 04$ & 5 & ELECTRIC COMMUNICATION TECHNIQUE \\
\hline & Sum & & 151 & \\
\hline
\end{tabular}

* \# : Number

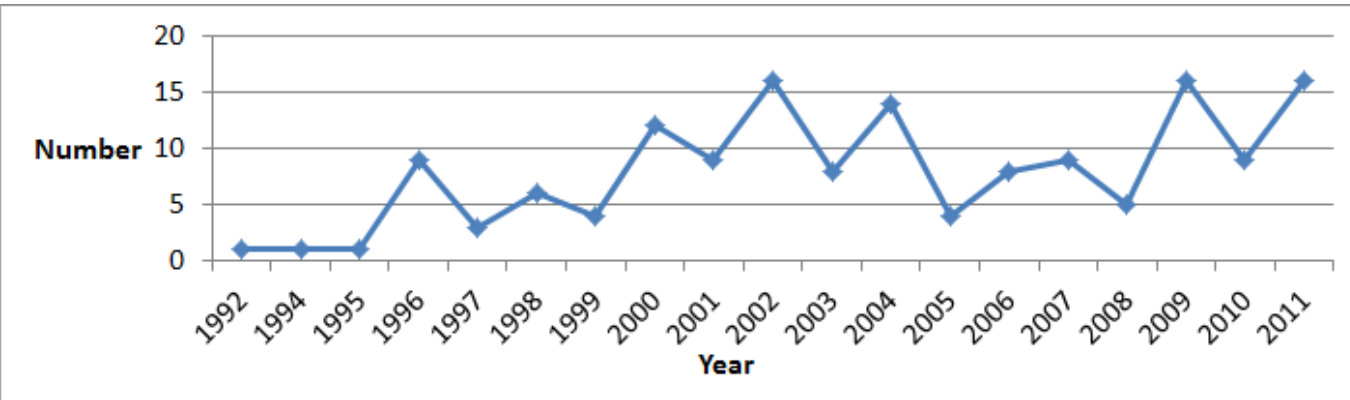

Figure 1. The number of patent by year

국제특허분류(IPC)는 전세계적으로 통용되고 있는 특 허문헌에 대해 국제적으로 통일된 분류를 하고 검색 을 할 수 있도록 하기위해 1954년 국제특허분류에 관
한 유럽조약의 규정에 의해 만들어졌다. 이후 1971년 Strasbourg 조약(IPC 조약)이 체결되어 국제특허분류 $(\mathrm{IPC})$ 를 이용하여 국가 간의 기술을 교류하고 외국특 
허문헌의 원활한 이용과 검색이 가능하게 되었다. 자 국의 형편에 따라 보조적인 분류체계를 혼용하기도 하지만, 유럽은 물론 미국, 일본 뿐 아니라 국내에서도 국제특허분류에 의한 분류체계를 기본적으로 표기하 고 있다. IPC 분류는 모두 8가지 섹션이 있으며, A 섹션은 생활필수품, $\mathrm{B}$ 는 분리, 혼합, $\mathrm{C}$ 는 화학, 야금, $\mathrm{D}$ 는 섬유, 지류, $\mathrm{E}$ 는 고정구조물, $\mathrm{F}$ 는 기계공학, 조명, 가열, 무기, 폭파, $\mathrm{G}$ 는 물리학, $\mathrm{H}$ 는 전기에 관련된 특 허를 나타낸다 ${ }^{11}$.

Table 1을 살펴보면, 체질관련 특허는 주로 생활필 수품(84건)과 물리학분야, 특히 산술논리연산분야48 건)로 나타났으며, 특이하게 고정구조물, 기계공학 분 야에 하나씩 있음을 알 수 있다. 고정구조물 분야에는 "건강관리를 위한 벽면, 천정 시공방법"이라는 특허 로, 체질별로 건물을 건축하는 방법에 대한 것이며, 기계공학 분야에는 "한의학적 체질 구분을 위한 3 차
원 정보 획득 장치 및 방법"이라는 제목의 특허로, 체 질정보를 획득하기 위해 피사체의 3차원 정보를 입력 받기 위한 장치를 개발하는 것이다.

Table 2는 연도별 IPC 클래스별 특허수를 살펴본 것이다. A61 클래스(위생학, 의학 또는 수의학)와 G06 클래스(산술 논리 연산, 계산, 계수, 필기 용구와 계산 기의 조합) 분야의 특허는 연도와 상관없이 꾸준히 발표되고 있음을 알 수 있다.

체질 특허의 내용적 면을 분석하기 위하여 체질전 문가 2 인과 컴퓨터공학 전공자 1 인에 의하여 체질 특 허 내용을 분석하고 각 특허를 분류하였다.(Table 3) 분류는 크게 4 가지인 진단, 치료, 응용, 정보제공으로 나뉘며, 체질진단방법 또는 체질관련 정보를 분석하 는 방법에 관한 것을 '진단', 체질에 따른 질병의 치료 에 관한 것을 '치료', 체질 정보를 이용하여 실생활에 응용한 것을 '응용', 마지막으로 체질 정보를 효과적으

Table 2. The Number of Each IPC Class by Year

\begin{tabular}{|c|c|c|c|c|c|c|c|c|c|c|c|c|c|}
\hline * & Total & $<2000$ & 2000 & 2001 & 2002 & 2003 & 2004 & 2005 & 2006 & 2007 & 2008 & 2009 & 2010 \\
\hline Total & 151 & 28 & 26 & 10 & 11 & 10 & 10 & 7 & 5 & 12 & 11 & 15 & 6 \\
\hline $\mathrm{A} 01$ & 1 & - & - & - & 1 & - & - & - & - & - & - & - & - \\
\hline A23 & 19 & 4 & 4 & 6 & 1 & 1 & - & 1 & 1 & - & 1 & - & - \\
\hline A41 & 7 & - & - & - & 1 & 4 & 1 & 1 & - & - & - & - & - \\
\hline A45 & 1 & - & - & - & - & - & - & - & - & - & 1 & - & - \\
\hline A47 & 1 & - & - & - & - & - & - & - & - & 1 & - & - & - \\
\hline A61 & 54 & 20 & 5 & 2 & 2 & 1 & 1 & 3 & 1 & 6 & 4 & 7 & 2 \\
\hline A63 & 1 & - & - & - & - & - & - & - & 1 & - & - & - & - \\
\hline $\mathrm{CO2}$ & 1 & - & - & - & - & - & - & - & 1 & - & - & - & - \\
\hline C11 & 1 & - & - & - & - & - & 1 & - & - & - & - & - & - \\
\hline $\mathrm{C} 12$ & 5 & - & - & 1 & 1 & 1 & - & - & - & - & - & 2 & - \\
\hline E04 & 1 & - & - & - & - & - & - & - & - & - & 1 & - & - \\
\hline F25 & 1 & - & - & - & - & - & - & - & - & - & - & 1 & - \\
\hline G01 & 2 & 2 & - & - & - & - & - & - & - & - & - & - & - \\
\hline G06 & 48 & 1 & 15 & 1 & 4 & 3 & 4 & 2 & 1 & 5 & 4 & 4 & 4 \\
\hline G07 & 2 & - & 1 & - & 1 & - & - & - & - & - & - & - & - \\
\hline G10 & 1 & - & - & - & - & - & 1 & - & - & - & - & - & - \\
\hline $\mathrm{HO}$ & 5 & 1 & 1 & - & - & - & 2 & - & - & - & - & 1 & - \\
\hline
\end{tabular}

*: IPC - Class/Year

Table 3. Classification of Patents

\begin{tabular}{ccc}
\hline Class & Sub-class & Description \\
\hline Diagnosis & - & $\begin{array}{c}\text { algorithm for diagnosis of constitution or analysis of } \\
\text { information according to constitution }\end{array}$ \\
\hline Treatment & medication, non-medication & treatment according to constitution \\
\hline Application & food, cloth, sale, etc & application using constitution \\
\hline Supporting of Information & - & 체질정보를 제공하는 시스템 \\
\hline
\end{tabular}


Table 4. The Number of Each Classification

\begin{tabular}{|c|c|c|}
\hline \multicolumn{2}{|c|}{ Classification } & \multirow{2}{*}{$\begin{array}{c}\text { Number } \\
69(45.52 \%)\end{array}$} \\
\hline Diagnosis & Diagnosis & \\
\hline \multirow{2}{*}{ Treatment } & Non-medication & $2(1.29 \%)$ \\
\hline & medication & $3(1.94 \%)$ \\
\hline \multirow{4}{*}{ Application } & Food & $23(47.10 \%)$ \\
\hline & Cloth & $7(4.52 \%)$ \\
\hline & Sale & $12(7.74 \%)$ \\
\hline & Etc & $11(7.33 \%)$ \\
\hline Supporting of Information & Supporting of Information & $27(17.42 \%)$ \\
\hline \multicolumn{2}{|c|}{ Sum } & 154 \\
\hline
\end{tabular}

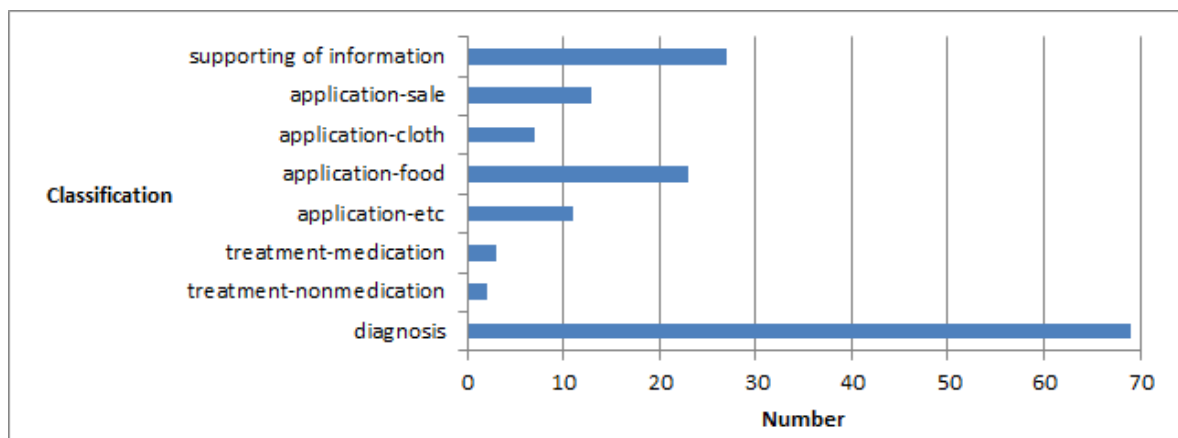

Figure 2. Graph of patent classification

로 제공할 수 있는 시스템 또는 그 방법들을 '정보제공' 으로 분류하였다.

Table 3의 분류에 의하여 151 건의 체질 특허를 분류 한 결과는 Table 4에서 볼 수 있다. 특허는 모두 151건 이지만, "사상체질 감별을 위한 설문지 작성 방법 및 상기 방법을 이용한 인터넷 비지니스 모델"과 같은 특허의 경우 '진단'과 '응용-판매'의 두 가지로 분류하 여 전체 태그 분류수가 154개였다. Table 4와 Figure 2 를 살펴보면, 대부분의 특허인 69 건(45.52\%)이 진단 에 관련된 것으로 나타났다. 다음으로 응용-식품이 23 건(47.10\%)으로 나타났다.

출원인 별 특허수를 조사한 결과는 Table 5 에서 볼 수 있다. Table 5에서 작성된 출원인 별 특허수는 전체 출원인 107인을 모두 살펴보기에는 그 수가 많으므로 2건 이상의 특허를 발표한 출원인을 중심으로 작성되 었다.

Table 5 를 살펴보면, 가장 많은 특허를 낸 출원인은 한국한의학연구원으로 모두 15건의 특허를 보유하고
있다. 다음으로 조한규가 8건 김상균, 엘지전자 주식 회사, 오용환, 정학년이 4건을 보유하고 있다. 같은

Table 5. The Number of Each Applicant

\begin{tabular}{clc}
\hline No. & \multicolumn{1}{c}{ applicant } & Number \\
\hline 1 & 가나정보 주식회사 & 2 \\
\hline 2 & 강성구 & 2 \\
\hline 3 & 김경순 & 2 \\
\hline 4 & 김성곤 & 2 \\
\hline 5 & 김종이 & 2 \\
\hline 6 & 이곤경 & 2 \\
\hline 7 & 조한주 & 2 \\
\hline 8 & 주식회사 엘지생활건강 & 2 \\
\hline 9 & 평성인 & 2 \\
\hline 10 & 학교법인 동의학원 & 2 \\
\hline 11 & 한국생명공학연구원 & 2 \\
\hline 12 & 김상균 & 4 \\
\hline 13 & 엘지전자 주식회사 & 4 \\
\hline 14 & 오용환 & 4 \\
\hline 15 & 정학년 & 4 \\
\hline 16 & 조한규 & 8 \\
\hline 17 & 한국 한의학 연구원 & 15 \\
\hline & $\quad$ Sum & 61 \\
\hline & $\quad$ &
\end{tabular}


발명가가 꾸준히 체질분야의 특허를 발명하는지를 알 아보기 위하여 연도별 출원인의 특허수를 살펴보았다 (Table 6).

Table 6을 살펴보면, 한국한의학 연구원은 2007년 체질관련 특허수가 처음 등록된 후 최근 많은 발명이 이루어졌다. 두 번째로 많은 특허를 보유한 조한규는 2000년대 초에 많은 발명을 하였으며, 2006년 이후에 는 특허가 등록되지 않고 있다. 최근 체질관련 발명에 관심을 보이는 출원인들은 강성구, 학교법인 동의학 원과 한국생명공학연구원등으로 보인다.

\section{IV. 考察}

맞춤의학과 전인적 관점의 의학에 대한 관심이 커 지면서, 사상체질의학에 대한 연구들도 활발하게 진 행되고 있으나, 대부분의 사상체질의학 연구는 논문 을 통해서만 발표되고 있다. 이에 비해, 최근 특허정보 를 연구개발 혁신활동의 주요 성과로 평가하기 시작 하면서 많은 연구자들이 자신의 연구 성과를 특허를 통해 발표한 후 논문을 통하여 발표하려는 노력을 하 고 있는 추세이다. 따라서 체질연구를 주제로 한 특허 동향을 분석함으로써, 최근 활발하게 연구되고 있는
체질 연구 동향은 물론 아직 연구 진행이 취약한 부분 까지 살펴볼 수 있을 것이다.

본 연구에서는 특허분석을 위해 윈텔립스 특허분 석 프로그램 ${ }^{10}$ 을 사용하여, 국내에서 등록된 모든 체 질 관련 특허를 조사하였다. 전처리 과정을 거쳐 모두 151 건의 특허를 수집하였으며, 이를 연도별 특허수와 추이, IPC 분류별 특허수와 연도별 IPC에 따른 특허수, 특허의 내용에 따른 분류, 출원인별 특허수, 연도별 출원인에 따른 특허수로 나누어 분석하였다.

본 연구에서의 분석을 살펴보면, 체질관련 특허는 체질을 진단하는 방법에 관한 특허가 69건으로 가장 많았으며, 연도별 IPC 클래스 분석과 테그 분석에서도 많은 A61(위생학, 의학 또는 수의학)과 G06(산술 논리 연산, 계산, 계수, 필기 용구와 계산기의 조합) 클래스 분야의 특허와 진단관련 특허가 꾸준히 발표되고 있 었다. 이는 실제 진료 시 체질 진단에 객관성이 미흡하 여 이를 극복하기 위해 진단 연구들이 많이 진행되고 있음을 뜻하며, 진단 영역에서도 $\mathrm{G06}$ 클래스에 해당 하는 "산술 논리 연산, 계산" 등을 활용한 연구가 많다 는 것을 알 수 있다. 특히 최근 들어 한국한의학연구원 을 중심으로 다학재간의 융합연구를 통하여 객관적 정보를 바탕으로 체질을 진단하고자 하는 연구가 진

Table 6. The Number of Each Applicant by Year

\begin{tabular}{|c|c|c|c|c|c|c|c|c|c|c|c|c|}
\hline$*$ & Total & $<$ & 2001 & 2002 & 2003 & 2004 & 2005 & 2006 & 2007 & 2008 & 2009 & 2010 \\
\hline Total & 151 & 54 & 10 & 11 & 10 & 10 & 7 & 5 & 12 & 11 & 15 & 6 \\
\hline 한국한의학연구원 & 15 & - & - & - & - & - & - & - & 3 & 2 & 7 & 3 \\
\hline 조한규 & 8 & - & 2 & 1 & - & 1 & 4 & - & - & - & - & - \\
\hline 김상균 & 4 & 4 & - & - & - & - & - & - & - & - & - & - \\
\hline 엘지전자 주식회사 & 4 & - & - & - & - & 3 & 1 & - & - & - & - & - \\
\hline 오용환 & 4 & 4 & - & - & - & - & - & - & - & - & - & - \\
\hline 정학년 & 4 & - & - & - & 4 & - & - & - & - & - & - & - \\
\hline 가나정보 주식회사 & 2 & 2 & - & - & - & - & - & - & - & - & - & - \\
\hline 강성구 & 2 & - & - & - & - & - & - & - & - & - & 2 & - \\
\hline 김경순 & 2 & - & 2 & - & - & - & - & - & - & - & - & - \\
\hline 김성곤 & 2 & 2 & - & - & - & - & - & - & - & - & - & - \\
\hline 김종이 & 2 & 1 & - & - & - & - & - & - & 1 & - & - & - \\
\hline 이곤경 & 2 & 2 & - & - & - & - & - & - & - & - & - & - \\
\hline 조한주 & 2 & - & 2 & - & - & - & - & - & - & - & - & - \\
\hline 주식회사 엘지생활건강 & 2 & - & - & - & - & - & 1 & - & 1 & - & - & - \\
\hline 평성인 & 2 & - & - & - & - & 1 & - & - & - & 1 & - & - \\
\hline 학교법인 동의학원 & 2 & - & - & - & - & - & - & - & - & 2 & - & - \\
\hline 한국생명공학연구원 & 2 & - & - & - & - & - & - & - & - & - & 2 & - \\
\hline
\end{tabular}

*: The first applicant/year 
행되면서 이 분야의 특허가 꾸준히 발표되고 있다.

이와 같이 진단 영역에 특허가 집중되어 있는 반면, 치료 영역의 특허는 상당히 적음을 확인할 수 있었다. 이를 통해 체질 치료 분야의 연구가 아직까지는 취약 하다는 것과 동시에 많은 연구 주제와 연구비가 투입 될 수 있는 미개척 분야임을 알 수 있다. 이와 같은 맥락에서 진단 영역에서도 산술 논리가 아닌 생화학, 유전자 분야를 활용한 부분 역시 아직 추가 연구의 여지가 많은 분야라 할 수 있다.

일반인을 주 대상으로 할 수 있다는 응용 분야에 있어서는 음식에만 집중되어 있는 현실이다. 인간의 사회성을 인식하고 건강은 물론 심리, 생활, 사회생활 등에 대한 내용도 다루고 있는 사상체질의학인만큼 응용 분야에 있어서도 음식뿐만 아니라 보다 다양한 결과물들을 도출할 수 있으리라 기대된다. 이를 위해 응용 분야에 있어서도 보다 다양한 연구 주제와 내용 등이 진입할 수 있으리라 생각된다.

\section{V. 感謝의 글}

이 논문은 2012년도 교육과학기술부의 재원으로 한국연구재단의 지원(N 0.20110027739)과 2012년도 한국한의학연구원 기관목적사업(Grant N 0. K 12070) 의 지원을 받아 수행된 연구임.

\section{VI. 參考文獻}

1. Robert K rulwich (2001-04-17). Cracking the Code of Life (Television Show). PBS. ISBN 1-5375-16-9.

2. Lee J. Longevity \& Life Preservation In Oriental Medicine. Seoul: Kyung Hee University Press. 1996.

3. 국내외 체질분야 연구 분석 - $\mathrm{KCl}$ 및 $\mathrm{SCl}$ 데이터 분석을 중심으로, 한국한의학연구원 체질의학연 구본부. 2011 (Korean)

4. Collins FS, Green ED, Guttmacher AE, Guyer MS. A vision for the future of genomics research. $N$ ature. 2003:22;835-847

5. Kim DH, Park SS, Shin YG, Jang DS. Forecasting the Diffusion of Technology using Patent Information: Focused on Information Security Technology for
N etwork-Centric W arfare. 한국콘텐트학회논문지. 2009:9. (K orean)

6. Hwang SH. Kim PR. A Study on the Projection of the IT-based Promising Technologies Utilizing Patent Database, 한국통신학회논문지. 2009:34. (K orean)

7. Jun SH. Technology Forecasting of Intelligent Systems using Patent Analysis. Journal of Intelligence and Information Systems. 2011:21(1) (Korean)

$8 \mathrm{Kim}$ PR, H wang SH. A Study on the Projection of the IT-based Promising Technologies Utilizing Patent Database. Korea Information and Communications Society. 2009:34:10. (K orean)

9. 2010년도 지식재산 백서. KOREAN INTELLECTUAL PROPERTY OFFICE. 2011. (Korean)

10. W intelips. Patent Theme Search \& Smart Analysis Solution. Available from:URL:http://www.wintelips.com.

11. Korean Intellectual Property Office. Available from: URL:http://www.kipo. go.kr/. 